\title{
Etkili Mikroorganizmaların Tüplü Toros Sediri (Cedrus libani A. Rich.) Fidanlarının Morfolojik Özelliklerine Etkisi
}

\author{
Sezgin AYAN ${ }^{1}$, Ebru ÇALIŞKAN ${ }^{2}$, Halil Barış ÖZEL ${ }^{3 *}$, Esra Nurten YER ÇELİK ${ }^{1}$, \\ Orhan GÜLSEVEN ${ }^{4}$, Ergin YILMAZ ${ }^{4}$ \\ ${ }^{1}$ Kastamonu Üniversitesi, Orman Fakültesi, Silvikültür ABD, 37100, Kastamonu \\ ${ }^{2}$ Kastamonu Üniversitesi, Fen Bilimleri Enstitüsü, Orman Mühendisliği ABD, 37100, Kastamonu \\ $3^{3 *}$ Bartın Üniversitesi, Orman Fakültesi, Silvikültür ABD, 74100, Bartın \\ ${ }^{4}$ Kastamonu Üniversitesi, Fen Bilimleri Enstitüsü, Sürdürülebilir Ormancılık Doktora Programı, Kastamonu
}

\section{Öz}

Bu çalışmada; Etkili mikroorganizmaların (EM) tüplü 2+0 yaşı ı Toros sediri (Cedrus libani A. Rich.) fidanlarının bazı morfolojik karakterleri üzerine etkisi belirlenmeye çalışılmıştır. Çalışmada; EM-1, EM-A (\%30, \%60, \%90 dozlarında), EM-5 ve EM-Gold (\%10, \%20 ve \%30 dozlarında) çeşitleri kullanılmıştır. Uygulamalar iki farklı zamanda gerçekleştirilmiştir. Birinci uygulama vejetasyon dönemi öncesi Nisan ayında; İkinci uygulama ise bitkilerin büyümesinin en aktif olduğu vejetasyon dönemi içinde Haziran ayında tesadüf parselleri deneme desenine göre üç tekerrürlü olarak gerçekleştirilmiştir. Uygulamalardan bir ay sonra işlemler tekrarlanmıştır. Fidanlara ait morfolojik ölçümler ikinci vejetasyon dönemi sonunda laboratuvar ortamında gerçekleştirilmiştir. Çalışma sonucunda elde edilen bulgulara göre; EM'lar, Toros sediri fidanlarının bazı morfolojik karakterleri üzerinde kontrol fidanlarına göre olumlu yönde farklılığa sebebiyet verdiği tespit edilmiştir. EM uygulamalarının orta ve yüksek dozlarının kök boğazı çapı (KBÇ), gövde taze ağırlığı (GTA), fidan taze ağırlığı (FTA), kuru kök yüzdesi (\%KKök) ve gürbüzlük indisi (GI) karakterleri üzerinde olumlu etkisi tespit edilmiştir. Ayrıca, EM uygulamasının zamanı açısından vejetasyon dönemi içinde yapılan aplikasyonun KBÇ ve \%KKök üzerinde olumlu etkisi saptanmıştır. Çalışma sonuçları ışı̆̆ında; EM'ların Toros sediri fidanı yetiştiriciliğinde fidan kalitesini arttırabileceği ve Toros sediri ile yapılan ağaçlandırmalar açısından da adaptasyon yeteneği yüksek fidan eldesine katkı sağlayabileceği kanaatine varılmıştır.

Anahtar kelimeler: Etkin mikroorganizma, Toros Sediri, fidan kalitesi, morfoloji.

\section{Influence of Effective Microorganisms on Morphological Characteristics of Taurus Cedar (Cedrus libani A. Rich.) Containerised Seedlings}

\begin{abstract}
In this study; It is aimed to determine on some morphological characters the degree of effect in $2+0$ aged of effective microorganisms (EM) in Taurus cedar (Cedrus libani A. Rich.) seedlings. In the study nursery conditions EM-1, EM-A (At doses of 10\%, 20\%, and 30\%), EM-5, EM-Gold (At doses of 10\%, 20\%, and 30\%) variants were used. Applications were carried out at two different times. 1st application before the vegetation period in April; The second application was carried out in June, which is the vegetation period when the plants are most active according to the randomized plot design with three replications. One month after the applications, the procedures were repeated. In the study, all morphological measurements of the seedlings were carried out at the end of the vegetation period in the laboratory environment. According to the findings obtained as a result of the study; in nursery environment, active microorganisms differed positively in Taurus cedar seedlings in terms of morphological characters compared to control seedlings. It has been determined that medium and high doses of EM applications have a positive effect on root collar diameter (RCD), stem fresh weight (SFW), seedling fresh weight (SFW), dry root percentage (\%DRP) and sturdiness index (SI) characters. In addition, in terms of the time of EM application, a positive effect of the application performed during the vegetation period was found to have a positive effect on RCD and \%DRP. In the results of the study; it has been concluded that effective microorganisms can increase the quality of seedlings in the propagation of Taurus cedar seedlings and provide with high adaptability in terms of in afforestation made with Taurus cedar seedlings.
\end{abstract}

Keywords: Effective microorganism, Taurus Cedar, seedling quality, morphology. 


\section{Giriş}

Türkiye’nin monopolündeki Toros sediri (Cedrus libani A. Rich.); Türkiye, Suriye ve Lübnan dağlarında deniz seviyesinden 1.400 ile $2.200 \mathrm{~m}$ yüksekliğe kadar geniş dikey amplitute gösteren, Toros orojenik kuşağında saf ve karışık meşcereler kuran görkemli bir orman ağacıdır (Ata, 1995; Quézel ve Médail, 2003; Ayan ve Yer, 2016; Ayan vd., 2018). Sedir zorlu kış şartlarına ve yaz aylarında meydana gelen yüksek sıcaklıklara oldukça toleranslı bir türdür. Yüksek tolerans özelliği Toros sedirini ağaçlandırma çalışmalarında sıkça tercih edilen bir tür haline getirmiştir (Ata, 1995). Toros sedirinin doğal yayılış yaptığı alanların dışında, Türkiye'nin beş farklı coğrafi bölgesinde 25 farklı il sınırları içerisinde başarılı plantasyonlarının var olması, plastisitesinin yüksek bir tür olduğunu teyit etmektedir (Ayan, 2015; Ayan vd., 2017).

Ağaçlandırmalarda kullanılacak fidanların kalitesi üzerinde; tüplü fidan kullanımının (Ayan, 2007), değişik yetiştirme ortamı materyallerinin (Ayan, 1999; 2001; 2002a; 2002b; Ayan vd., 2005a; Ayan ve Tüfekçioğlu, 2006; Ayan ve Tilki, 2007), yavaş yarayışlı gübrelerin (Ayan, 1998), farklı yetiştirme süreçlerinin -"sera-açık alan-gölgelik alan” (Ayan vd., 2000), fidanlık ekolojik koşullarına göre belirlenmiş fidan gelişim evrelerine dayalı kültürel işlemlerin (Demircioğlu ve Ayan, 2004; Ayan vd., 2005b; Yer ve Ayan, 2011) etkisi olduğu değişik çalışmalarda belirtilmiştir.

Türkiye fidanlıklarında yapılan fidan kalitesi araştırmalarında gerek ekonomik gerek zaman tasarrufu ve pratikliği nedeniyle morfolojik fidan kalite özelliklerinin tayinine yönelik araştırmalar öne çıkmaktadır. Türkiye'de bu anlamda, karaçam (Ayıntapl1, 1995; Avanoğlu vd., 2005; Yer ve Ayan, 2011), sarıçam (Demircioğlu vd., 2004), Toros sediri (Eler vd., 1993; Ayıntaplı, 1995; Yer ve Ayan, 2011), Doğu kayını (Gülseven vd., 2019) ve Doğu ladini (Genç, 1992; Ayan, 2002a), Akdeniz ve Arizona servisi (Ayan vd., 2020a), fıstıkçamı (Ayan vd., 2020b) ile geniş yapraklı orman ağacı türlerinde (Şevik vd., 2003; Ayan vd., 2020c) fidan kalite sınıflandırılması üzerine detaylı çalışmalar gerçekleştirilmiştir.

Özellikle toprak verimliliği, ağaçlandırma sahalarında kullanılacak fidanların kalitesi üzerinde de etkilidir. Ancak, Türkiye'deki fidanlıkların en önemli sorunlarından biri fidanlık topraklarının düşük verimlilikte olmasıdır (Atik, 2013). Fidanlıklarda uzun süreli yanlış yönetim, fidanlık topraklarının organik madde eksikliği ve suni gübre kullanımındaki yanlışlıklar yetiştirilen fidanların kalitesini düşürerek fidanların verimliliğinin azalmasına sebep olmaktadır (Yılmaz, 1988). Ayrıca, tarım alanlarında olduğu gibi orman fidanlıklarında da kimyasal gübrelerin kullanılması, toprağın doğal yapısını doğrudan ya da dolaylı olarak olumsuz etkilemektedir. Bu nedenle son yıllarda fidanlıkların mevcut verimini arttırmak ve kaliteli fidan üretmek için biyolojik ve doğal materyallere olan ihtiyaç daha da önem kazanmıştır.

Yürütülen birçok çalışmada orman fidanlıklarında ve tarımsal üretimde kullanılan kimyasal gübrelerin, bitki besin maddesini karşılamada olumlu sonuçlar verdiğine ait sonuçlar ifade edilmiştir (Özdemir, 1989; Kulaç, 2016). Fakat, kullanılan kimyasal gübrelerin veya pestisitlerin insan sağlı̆̆ına ve tabiata olan zararlı etkileri nedeniyle son yıllarda Etkili Mikroorganizma [(EM (etkili, aktif, efektif, ya da yararlı mikroorganizma)] teknolojisi gelişmeye başlamıştır. Bu teknoloji, kimyasal gübreler ve pestisitlerin yoğun kullanılmaya başlandığı 1930'lu yıllarda Japon filozof ve doğa bilimci Mokichi Okada tarafından kimyasalların uzun vadedeki zararları dikkate alınarak geliştirilmiştir.

EM'ler, esas olarak toprakta yaygın olarak bulunan laktik asit bakterileri, fotosentetik bakteriler, mayalar ve aktinomisetlerden oluşan mikrobiyal inokülanlardır (Zimmermann ve Kamukuenjandje, 2008). Toprak kalitesini ile bitkilerin büyümesini ve verimini arttırmak, atık suyun arıtılması, zararlıların ve hastalıkların kontrolü, hayvan büyümesinin iyileştirilmesi, kompost üretiminin arttırılması ve hasat edilen ürünlerin raf ömrünün uzatılması amacıyla yaygın olarak toprakta kullanılan ve bitkilere inokülant olarak uygulanan, doğal ve yararlı mikroorganizmaların karışık kültürlerinden oluşmaktadır (Suzuki, 1985; Higa ve Parr, 1994; Iwaishi, 1994; Iwahori ve Nakagawara, 1996; Zimmermann ve Kamukuenjandje, 2008). Daha çok tarımda kullanılan EM’ler doğal tarımın önemli bir parçası haline gelmiştir (Arakawa, 1985; Suzuki, 1985; Higa, 1998). EM, çok sayıda mikrobiyal türden oluşmasına rağmen, baskın popülasyonlar laktik asit bakterileri, mayalar, aktinomikler ve fotosentetik bakterilerdir.

EM'in tarımsal ürün verimliliği üzerindeki olumlu etkileri ile ilgili birçok çalışma yürütülmüştür. Bu mikroorganizmaların olağanüstü etkileri üzerine Chagas vd., (2001) papatyada, Hollanda ve Avusturya'da çimenler üzerine (Daly ve Stewart, 1999; Fujita, 2000) Japonya'da ise elma üzerine (Fujita, 2000) çalışmalar yapılmıştır. Fidan kalitesi üzerine ise Atik (2013)'de Pinus nigra'da EM'nin fidan boyu ve kök boğaz çapına olan etkisi üzerine bir çalışma gerçekleştirmiş̧ir. 
Günümüzde gübrelemenin fidan kalitesine etkisiyle alakalı birçok çalışma mevcuttur. Fakat gübrelemenin ileri bir teknolojisi olarak varsayılan ve Avrupa ülkelerinde birçok alanda, özellikle de tarım alanında kullanımı tercih edilen EM’lerin orman ağacı fidan kalitesine etkisine ait çalışmalar oldukça sınırlıdır.

Bu çalışmada gerek doğal yayılış alanı içerisinde gerekse dışındaki birçok ekoloji de yüksek uyum kabiliyeti gösteren Türkiye'deki ağaçlandırma çalışmalarında en çok tercih edilen ve plastisitesi yüksek türlerden biri olan Toros sediri fidanlarına EM uygulamasının morfolojik kalite özelliklerine etkisini değerlendirmek hedeflenmiştir.

\section{Materyal ve Metot}

\subsection{Materyal}

Eğirdir orijinli 2+0 yaşlı polietilen tüplü Toros sediri fidanları üzerinde yürütülen çalışma; Kastamonu Orman Bölge Müdürlüğü’ne bağlı Daday Orman Fidanlığında gerçekleştirilmiştir. Çalışmanın gerçekleştirildiği fidanlığa ait özet bilgiler Tablo 1'de verilmiştir.

Tablo 1. Daday Orman Fidanlığı’na ait genel bilgiler.

\begin{tabular}{ll}
\hline Özellikler & Değerler \\
\hline Enlem & $41^{\circ} 22^{\prime} 16^{\prime \prime}$ \\
Boylam & $33^{\circ} 46^{\prime} 38^{\prime \prime}$ \\
Bakı & Güney \\
Denizden Yükseklik (m) & 800 \\
Yıllık Ort. Sıcaklık ( $\left.{ }^{\circ} \mathbf{C}\right)$ & 9,9 \\
Yıllık Max. Sıcaklık ( $\left.{ }^{\circ} \mathbf{C}\right)$ & 19,9 \\
Yıllık Min. Sıcaklık ( $\left.{ }^{\circ} \mathbf{C}\right)$ & $-0,3$ \\
Yıllık Yağıș (mm) & 611 \\
Yıllık Ortalama Bağıl Nem (\%) & 50 \\
Vejetasyon Dönemi & Mayıs-Ekim \\
\hline
\end{tabular}

Polietilen tüplerde yetiştirilen fidanlar için $\% 60$ mineral toprak, $\% 5$ ince kum, $\% 20$ humus ve $\% 15$ yanmış ahır gübresinden oluşan harç karışımı kullanılmıştır.

\subsection{Metot}

\subsubsection{Etkili mikroorganizmaların hazırlanması}

Fidanlıkta araştırma objesi olarak ele alınan fidanlara rutin fidanlık kültürel işlemleri uygulanmış, sulama işlemi yağmurlama sistemi ile gözleme dayalı olarak haftada bir yapılmıştır. Araştırma, açık alan şartlarında "Tesadüf Parselleri Deneme Desenine” göre oluşturulmuştur.

Çalışmada; EM-1, EM-5, EM-A ve EM-Gold olmak üzere dört farklı EM ürünü kullanılmıştır. Ürünlerden EM1, EM-A'dan \%30, \%60, \%90 oranında ve EM-5, EM-Gold ürünlerinden \%10, \%20 ve \%30 oranlarında (düşük, orta ve yüksek doz olarak ayarlanmıştır) 1,5 l kaplara solüsyonlar hazırlanmıştır. Dört farklı ürünün 3 farklı konsantrasyonuna ait toplam 12 farklı işlem olarak fidanlara uygulanmıştır (Tablo 2).

Tablo 2. EM çeşit ve dozlarının uygulama seviyeleri.

\begin{tabular}{llll}
\hline \multirow{2}{*}{ EM Çeşidi } & Doz (\%) & & \\
\cline { 2 - 4 } & Düşük & Orta & Yüksek \\
\hline EM-1 & 30 & 60 & 90 \\
EM-A & 30 & 60 & 90 \\
EM-5 & 10 & 20 & 30 \\
EM-Gold & 10 & 20 & 30 \\
\hline
\end{tabular}


Çalışmada kullanılan EM'leri özellikleri ise aşağıda belirtilmiştir;

EM-1; Tarımda uygulanan ana ürün olan ve EM'nin bütün faydalı özelliklerini içermektedir (URL-1, 2018). İçeriği; \%3 Molas, \%1 laktik asit bakterisi (Lactobacillus casei) ve \%96 sudur (URL-2, 2021).

EM-A; Hastalık ve zararlılara, düşük sıcaklık ve donlara karşı bitkinin direnci arttıran enzimler, antioksidan maddeler, organik asitler, biyoaktif maddeler, mineraller, doğal hormonlar ve diğer yararlı maddeler içermektedir (URL-1, 2018). İçeriğinde; laktik asit bakterileri (Lactobacillus fermentum, L. plantarum, L. rhamnosus, L. casei ve L. delbrueckii), mayalar (Saccharomyces cerevisiae), fototrofik bakteriler (Rhodopseudomonas palustris) ile heterotrofik bakteri (Bacillus subtilis) ve 3,5 pH altında yaşayabilen yararlı organizmalar mevcuttur (URL-3, 2021).

EM-5; Melas ve EM-1 ile fermente olmuş bir karışımdır. Kaliteli bir sıvı mikrobiyal gübre, yardımcı bitki besin maddesi, hastalık ve zararlılara karşı direnci arttıran, sürekli uygulandığında kimyasal tarım ilaçları gereksinimini yok denecek kadar azaltan ve çimlenmeden sonra, hastalık ve zararlılar ortaya çıkmadan önce kullanılan önemli bir etkin mikroorganizma grubudur (URL-1, 2018). Muhteviyatında laktik asit bakterileri (Lactobacillus delbrueckii, L. plantarum, L. rhamnosus, L. casei), mayalar (Saccharomyces cerevisiae) ve fototrofik bakteriler (Rhodopseudomonas palustris) mevcuttur (URL-4, 2021).

EM-Gold; İnsanlar için üretilmiş antioxidan maddeler ve çeşitli vitaminler içermektedir (URL-1, 2018). Su, mercan kireci ve nigari karışımında mikroorganizmalar tarafından fermente edilmiş şeker kamışı pekmezi ve maya ekstraktı bazlı özel bir üründür (URL-5, 2021).

EM uygulaması, tüpte gelişimini sürdüren 2+0 yaşlı tüplü fidanların henüz vejetasyon dönemine girmeden önce Nisan ayında ve fidanların büyümelerinin en aktif olduğu evre (hızlı gelişim evresi) olan Haziran ayının ilk haftasında direk fidanların toprak üstü aksamına ve tüpün yüzeyindeki tüp harcına pülverize edilmek suretiyle gerçekleştirilmiştir. Her işlem 3 tekrarlı olarak her parsel 10 fidanla temsil edilecek şekilde deneme kurulmuştur. İki farklı uygulama zamanında (vejetasyon öncesi ve vejetasyon dönemi içinde) dört adet EM çeşidi, üç farklı dozda uygulanmıştır.

İlk deneme alanı için vejetasyon dönemine girmeden 2017 Nisan ayının ilk haftasında her bir parsele spreyleme yoluyla EM çözeltileri muamele edilmiştir. 2. uygulama bu işlemden 1 ay sonra yani Mayıs ayının ilk haftasında tekrar edilmiştir. İkinci deneme alanı için ise vejetasyon döneminde 2017 Haziran ayının ilk haftasında, her bir parsele spreyleme yoluyla EM çözeltisi muamele edilmiştir. 2. uygulama bu işlemden 1 ay sonra Temmuz ayının ilk haftasında tekrar edilmiştir.

\subsubsection{Fidan morfolojik özellikleri}

Çalışmada kullanılan fidanların EM uygulaması öncesi kök boğazı çapı ve boy gelişimleri ölçülmüştür. 2. deneme alanı için ise vejetasyon dönemi içerisinde Haziran 2017'de ölçümler alınmıştır. Uygulamalar yapıldıktan bir vejetasyon dönemi sonrasında 2018 yılı Ocak ayında uygulamalara ait gelişimlerin görülebilmesi için fidanlarda tekrar çap ve boy gelişimleri ölçülmüştür. Diğer morfolojik ölçümlerin tamamlanması için her uygulama ve kontrol grubuna ait 10’ar adet fidanda ölçümler yapılmıştır.

2018 yılının Ocak ayında, 250 adet fidanda dal sayıları (FDS) (gövde üzerinde 1 cm'den uzun dallar), terminal sürgün üzerindeki tomurcuk adedi (TSÜTA) ölçümleri yapılmış ve hemen akabinde laboratuvara taşınan fidanlar; kök boğazlarından kesilmiştir. Kök boğazı çapları (KBÇ) 0,1 mm hassasiyetindeki kumpas yardımıyla ölçülmüştür. Kesilmiş olan boğaz kısmı üzerinden fidan boyu (FB) ölçülmüş, kök ve gövde taze ağılıkları (KTA, GTA) 0,001 gr hassasiyetle tartılmıştır. Uygulamaların yapıldığı fidanlarda taze ağırlıkları ölçülmüş kök ve gövde kısımları etiketlenerek önceden hazırlanmış kurutma fırınında $102 \pm 2{ }^{\circ} \mathrm{C}$ 'de 24 saat kurutulmuştur. Fırın kurusu haldeki kök ve gövde kuru (KKA ve GKA) (Ayan, 2002).

Ölçümü yapılan FB, KBÇ, DS, TSÜTA, GTA, KTA, GKA ve KKA değerleri yardımı ile fidan taze ağırlığ1 (FTA), fidan kuru ağırlığı (FKA), gürbüzlük indisi (Gİ), katlılık indisi (Kİ), \%Kkök (kuru kök yüzdesi) ve Dickson kalite indisi (DKİ) değerleri hesaplanmış ve ayrıca, fidan kalite indislerince uygulamaların başarıları incelenmiştir.

Gürbüzlük indisi (GI): Fidan boyunun (cm değeri mm'ye çevrilerek) kök boğazı çapına (mm) oranlanması ile elde edilir (Aphalo ve Rikala, 2003). Gürbüzlük indisi kalite ölçütleri; 50>Gİ ise, kaliteli fidan, 60>Gİ $>50$ ise 2. 
sınıf fidan ve GI> 60 için ise ıskarta, 3.sınıf fidan kategorisi baz alınarak değerlendirme yapılmıştır (Yahyaoğlu ve Genç, 2007).

$$
\text { Gİ = Fidan gövde boyu (mm) / Kök boğaz çapı (mm) }
$$

Katlılık İndisi (Kİ): Ölçülen fidan gövde kuru ağırlığının, kök kuru ağırlığına oranlanması ile elde edilen değerdir (Ayan, 2002a). Katlılık indisi değerlerine göre sınıf aralıkları; 3>KI: 1 sınıf fidan; 4>Kİ>3: 2. sınıf fidan ve $\mathrm{KI}>4$ ise 1skarta, 3.sınıf fidan olarak değerlendirilmiştir.

$$
\mathrm{KI}=\mathrm{GKA} / \mathrm{KKA}
$$

Kök yüzdesi (\%KKök): Fidana ait kök kuru ağırlık değerinin fidana ait toplam kuru ağırlık değerine oranlanmasiyla bulunur ve yüzde olarak ifade edilir (Ayan, 1999).

$$
\text { \%KKök= KKA (gr) / FKA (gr) x } 100
$$

Dickson Kalite İndeksi (DKİ): Fidan kuru ağırlık değerinin, Gürbüzlük indisi ile katlılık değeri toplamına bölünmesi ile elde edilen değerdir (Ayan, 2002; Mohamed, 2013). DKİ aşağıdaki Eşitlik 1'deki formül kullanılarak hesaplanmıştır; 1'e yakın ve 1'den büyük değerler kaliteli fidan olarak değerlendirilmiştir (Dickson vd., 1960).



\subsection{3. İstatistiki değerlendirmeler}

Ölçülen ve hesaplanan bütün morfolojik değişkenler üzerine EM çeşidi, dozu, uygulama zamanı faktörlerinin bireysel ve etkileşimli etkisini ortaya koymak için çoklu varyans analizi ve değişkenlere göre işlem mukayesesi için de Duncan çoklu testi SPSS paket programı yardımıyla uygulanmıştır. Sayılarak ve yüzde olarak elde edilen değişkenlerin verilerini normal dağılıma yaklaştırmak için gerekli arcsin ve logaritmik transformasyonlar uygulanmıştır.

\section{Bulgular}

Fidanlarında; FB, KBÇ, DS, TSÜTA, GTA, KTA, GKA ve KKA karakterleri ölçülüp-tartılmış ayrıca, FTA,

\begin{tabular}{|c|c|c|c|c|c|c|c|c|c|c|c|c|c|c|}
\hline \multirow[t]{2}{*}{ Ölçüm } & \multicolumn{2}{|c|}{$\begin{array}{l}\text { Uygulama } \\
\text { Zamanı }\end{array}$} & \multicolumn{2}{|c|}{ EM Dozu } & \multicolumn{2}{|c|}{ EM Çeşidi } & \multicolumn{2}{|c|}{$\begin{array}{l}\text { Uygulama } \\
\text { Zamanı x } \\
\text { EM Dozu }\end{array}$} & \multicolumn{2}{|c|}{$\begin{array}{l}\text { Uygulama } \\
\text { Zamanı x EM } \\
\text { Çeşidi }\end{array}$} & \multicolumn{2}{|c|}{$\begin{array}{l}\text { EM Dozu x } \\
\text { EM Çeşidi }\end{array}$} & \multicolumn{2}{|c|}{$\begin{array}{l}\text { Uygulama } \\
\text { Zamanı x } \\
\text { EM Dozu x } \\
\text { EM Çeșidi } \\
\end{array}$} \\
\hline & $\mathbf{F}$ & $\mathbf{P}$ & $\mathbf{F}$ & $\mathbf{P}$ & $\mathbf{F}$ & $\mathbf{P}$ & $\mathbf{F}$ & $\mathbf{P}$ & $\mathbf{F}$ & $\mathbf{P}$ & $\mathbf{F}$ & $\mathbf{P}$ & $\mathbf{F}$ & $\mathbf{P}$ \\
\hline FB & 0,30 & 0,57 & 2,78 & 0,06 & 0,59 & 0,61 & 0,49 & 0,61 & 2,92 & $0,03^{*}$ & 1,16 & 0,32 & 0,99 & 0,42 \\
\hline KBÇ & 5,40 & $0,02 *$ & 4,89 & $0,01^{*}$ & 0,10 & 0,95 & 1,51 & 0,22 & 5,43 & $0,00^{* *}$ & 0,53 & 0,78 & 1,66 & 0,13 \\
\hline DS & 3,17 & 0,07 & 2,93 & 0,05 & 0,12 & 0,94 & 0,01 & 0,98 & 1,91 & 0,12 & 1,30 & 0,25 & 1,47 & 0,18 \\
\hline TSÜTA & 1,98 & 0,16 & 0,02 & 0,97 & 0,73 & 0,53 & 0,90 & 0,40 & 0,07 & 0,97 & 0,30 & 0,93 & 1,05 & 0,38 \\
\hline GTA & 1,92 & 0,16 & 3,41 & $0,03^{*}$ & 0,39 & 0,75 & 0,59 & 0,55 & 3,35 & $0,02 *$ & 0,11 & 0,99 & 0,16 & 0,98 \\
\hline KTA & 2,00 & 0,15 & 3,34 & $0,03^{*}$ & 3,88 & $0,01^{*}$ & 0,15 & 0,86 & 2,10 & 0,1 & 0,66 & 0,68 & 1,70 & 0,12 \\
\hline FTA & 0,01 & 0,90 & 3,44 & $0,03^{*}$ & 1,88 & 0,13 & 0,29 & 0,74 & 2,86 & $0,03^{*}$ & 0,43 & 0,85 & 0,71 & 0,64 \\
\hline GKA & 2,26 & 0,13 & 1,51 & 0,22 & 1,16 & 0,32 & 0,92 & 0,39 & 1,99 & 0,11 & 0,33 & 0,91 & 0,30 & 0,93 \\
\hline KKA & 2,26 & 0,13 & 1,51 & 0,22 & 1,16 & 0,32 & 0,92 & 0,39 & 1,99 & 0,11 & 0,33 & 0,91 & 0,30 & 0,93 \\
\hline FKA & 0,00 & 0,98 & 2,91 & 0,05 & 2,32 & 0,07 & 0,78 & 0,45 & 1,98 & 0,11 & 0,52 & 0,79 & 0,63 & 0,70 \\
\hline \%KKök & 15,1 & $0,00 * *$ & 3,07 & $0,04 *$ & 4,18 & $0,00 * *$ & 1,69 & 0,18 & 2,41 & 0,06 & 1,58 & 0,15 & 4,13 & 0,07 \\
\hline Gí & 5,39 & 0,39 & 0,72 & $0,00^{* *}$ & 0,20 & 0,89 & 0,84 & 0,43 & 1,28 & 0,00 & 4,21 & 0,26 & 2,10 & 0,05 \\
\hline KI & 14,0 & $0,00 * *$ & 3,51 & $0,03^{*}$ & 3,74 & $0,01^{*}$ & 1,74 & 0,17 & 2,23 & 0,08 & 1,55 & 0,16 & 3,59 & 0,02 \\
\hline DKI & 0,23 & 0,63 & 2,55 & 0,08 & 3,21 & $0,02 *$ & 4,59 & 0,01 & 2,69 & $0,04 *$ & 2,08 & 0,05 & 0,66 & 0,67 \\
\hline
\end{tabular}
FKA, \%KKök, DKİ, Kİ ve Gİ değerleri hesaplanmıştır. Fidanlara uygulanmış olan EM işlem çeşidi, doz ve uygulama zamanının fidan morfolojik karakterleri üzerindeki etkisi Tablo 3’te verilmiştir (Tablo 3).

Tablo 3. Fidan morfolojik özelliklerine ait varyans analizi sonuçları. 
EM uygulama zamanının KBÇ, \%KKök ve Kİ değişkenleri üzerinde; Uygulama dozunun KBÇ, GTA, KTA, FTA, \%KKök, Gİ ve Kİ değişkenleri üzerinde; EM çeşidinin ise KTA, \%KKök, Kİ ve DKİ değişkenleri üzerinde anlamlı farklılıklar oluşturduğu tespit edilmiştir. Ayrıca, Uygulama zamanı x EM çeşidi işlem kombinasyonu; FB, KBÇ, GTA, FTA ve DKİ değerleri üzerinde anlamlı farklılıklar oluşturmuştur (Tablo 3). EM çeşidi, dozu ve uygulama zamanının bireysel etkilerine ait Duncan çoklu test sonuçları Tablo 4'te, uygulama zamanı x EM çeşidi ikili faktör etkileşiminin Duncan çoklu test sonuçları ise Tablo 5’te verilmiştir. 
Tablo 4. Morfolojik ölçümlere ait EM çeşidi, doz ve uygulama zamanına göre Duncan testi sonuçları.

\begin{tabular}{|c|c|c|c|c|c|c|c|c|c|c|c|c|c|c|}
\hline \multirow{2}{*}{ EM Çeşidi } & FB & KBÇ & DS & TSÜTA & GTA & KTA & FTA & GKA & KKA & FKA & \%KKök & Gí & Ki & DKİ \\
\hline & \multicolumn{14}{|c|}{ Aritmetik Ortalama $(\mathrm{X})$ \& Standart Hata $\left(\mathrm{S}_{\mathrm{x}}\right)$} \\
\hline Kontrol & $18,1 \pm 0,64$ & $4,6 \pm 0,18$ & $7,60 \pm 0,65$ & $3,8 \pm 0,26$ & $5,6 \pm 0,38$ & $4,4 \pm 0,32 \mathrm{ab}$ & $10,2 \pm 0,68$ & $3,2 \pm 0,19$ & $3,3 \pm 0,23$ & $6,6 \pm 0,4$ & $50,3 \pm 0,7 \mathrm{ab}$ & $45,3 \pm 1,5$ & $1 \pm 0,02 \mathrm{ab}$ & $0,5 \pm 0,1 \mathrm{~b}$ \\
\hline EM-1 & $18,8 \pm 0,35$ & $4,9 \pm 0,10$ & $7,22 \pm 0,40$ & $3,7 \pm 0,19$ & $4,8 \pm 0,17$ & $4,6 \pm 0,21 \mathrm{a}$ & $9,4 \pm 0,37$ & $3,0 \pm 0,10$ & $3,3 \pm 0,15$ & $6,4 \pm 0,2$ & $52,3 \pm 0,6 a$ & $38,1 \pm 0,9$ & $1,1 \pm 0,02 \mathrm{a}$ & $0,6 \pm 0,1 \mathrm{ab}$ \\
\hline EM-5 & $18,7 \pm 0,03$ & $4,9 \pm 0,08$ & $7,18 \pm 0,35$ & $3,4 \pm 0,24$ & $4,9 \pm 0,18$ & $4,2 \pm 0,13 a b$ & $8,8 \pm 0,28$ & $2,8 \pm 0,09$ & $3,0 \pm 0,11$ & $5,8 \pm 0,1$ & $50,1 \pm 0,7 \mathrm{ab}$ & $38,5 \pm 0,7$ & $1 \pm 0,03 \mathrm{ab}$ & $0,6 \pm 0,1 \mathrm{ab}$ \\
\hline EM-A & $19,0 \pm 0,35$ & $4,9 \pm 0,08$ & $7,10 \pm 0,39$ & $3,8 \pm 0,18$ & $4,7 \pm 0,15$ & $4,0 \pm 0,15 \mathrm{ab}$ & $9,2 \pm 0,28$ & $3,1 \pm 0,10$ & $2,9 \pm 0,08$ & $6,4 \pm 0,1$ & $50,6 \pm 0,6 \mathrm{ab}$ & $38,1 \pm 0,8$ & $1 \pm 0,02 \mathrm{ab}$ & $0,5 \pm 0,1 \mathrm{~b}$ \\
\hline EM-GOLD & $19,3 \pm 0,33$ & $5,1 \pm 0,10$ & $7,44 \pm 0,41$ & $3,7 \pm 0,22$ & $4,7 \pm 0,17$ & $3,8 \pm 0,08 \mathrm{c}$ & $8,4 \pm 0,33$ & $2,8 \pm 0,09$ & $2,9 \pm 0,12$ & $5,7 \pm 0,2$ & $49,2 \pm 0,8 \mathrm{~b}$ & $38,8 \pm 0,7$ & $1 \pm 0,04 \mathrm{~b}$ & $0,5 \pm 0,1 \mathrm{~b}$ \\
\hline $\begin{array}{l}\text { Uygulama } \\
\text { Dozu }\end{array}$ & \multicolumn{14}{|c|}{ Aritmetik Ortalama $(\mathrm{X})$ \& Standart Hata $\left(\mathrm{S}_{\mathrm{x}}\right)$} \\
\hline Kontrol & $18,1 \pm 0,6$ & $4,6 \pm 0,2 \mathrm{~b}$ & $7,6 \pm 0,6$ & $3,8 \pm 0,2$ & $4,6 \pm 0,3 \mathrm{~b}$ & $4,0 \pm 0,3 b$ & $8,6 \pm 0,7 \mathrm{~b}$ & $3,2 \pm 0,2$ & $3,4 \pm 0,2$ & $6,6 \pm 0,5$ & $50,3 \pm 0,7 \mathrm{ab}$ & $45,3 \pm 1,5 a$ & $1 \pm 0,02 \mathrm{~b}$ & $0,62 \pm 0,01$ \\
\hline Düşük & $18,7 \pm 0,3$ & $4,8 \pm 0,3 \mathrm{~b}$ & $6,5 \pm 0,3$ & $3,7 \pm 0,2$ & $4,5 \pm 0,1 b$ & $3,8 \pm 0,2 b$ & $8,3 \pm 0,3 \mathrm{~b}$ & $2,8 \pm 0,1$ & $2,8 \pm 0,1$ & $5,6 \pm 0,1$ & $49,5 \pm 0,7 \mathrm{ab}$ & $39,9 \pm 0,8 b$ & $1,1 \pm 0,03 \mathrm{a}$ & $0,58 \pm 0,01$ \\
\hline Orta & $19,5 \pm 0,3$ & $5,1 \pm 0,1$ a & $7,4 \pm 0,3$ & $3,7 \pm 0,2$ & $5,5 \pm 0,2 a$ & $4,3 \pm 0,1 \mathrm{ab}$ & $9,8 \pm 0,3 \mathrm{ab}$ & $3 \pm 0,1$ & $3,1 \pm 0,1$ & $6,2 \pm 0,2$ & $50,7 \pm 0,9 \mathrm{ab}$ & $38,6 \pm 0,6 a b$ & $1 \pm 0,03 \mathrm{~b}$ & $0,60 \pm 0,01$ \\
\hline Yüksek & $18,6 \pm 0,3$ & $5,1 \pm 0,3$ a & $7,6 \pm 0,2$ & $3,6 \pm 0,2$ & $5,6 \pm 0,1 \mathrm{a}$ & $4,3 \pm 0,1 \mathrm{ab}$ & $9,9 \pm 0,2 \mathrm{ab}$ & $2,9 \pm 0,05$ & $3,2 \pm 0,1$ & $6,2 \pm 0,2$ & $51,4 \pm 0,5 a$ & $36,8 \pm 0,7 \mathrm{c}$ & $1 \pm 0,02 \mathrm{~b}$ & $0,60 \pm 0,005$ \\
\hline $\begin{array}{l}\text { Uygulama } \\
\text { Zamanı }\end{array}$ & \multicolumn{14}{|c|}{ Aritmetik Ortalama (X) \& Standart Hata $\left(\mathrm{S}_{\mathrm{x}}\right)$} \\
\hline Nisan & $19,9 \pm 0,25$ & $4,9 \pm 0,1 b$ & $7,6 \pm 0,25$ & $3,5 \pm 0,15$ & $5 \pm 0,11$ & $4,1 \pm 0,1$ & $9,1 \pm 0,20$ & $3,1 \pm 0,06$ & $3, \pm 0,07$ & $6,1 \pm 0,1$ & $49,1 \pm 0,5 b$ & $39,2 \pm 0,6$ & $1,1 \pm 0,03 a$ & $0,60 \pm 0,007$ \\
\hline Haziran & $18,8 \pm 0,23$ & $5,1 \pm 0,6 a$ & $6,8 \pm 0,27$ & $3,8 \pm 0,13$ & $4,7 \pm 0,12$ & $4,3 \pm 0,1$ & $9 \pm 0,24$ & $2,8 \pm 0,07$ & $3 \pm 0,09$ & $6,1 \pm 0,2$ & $52,1 \pm 0,5 a$ & $39,2 \pm 0,6$ & $1 \pm 0,02 \mathrm{~b}$ & $0,60 \pm 0,07$ \\
\hline
\end{tabular}

FB: Fidan boyu, FKA: Fidan kuru ağırlığı, KTA: Kök taze ağırlığı, DKİ: Dickson kalite indisi, KBÇ: Kök boğaz çapı, FDS: Fidan dal sayısı, GKA: Gövde kuru ağırlı̆̆ı, Gİ: Gürbüzlük indisi,

KKA: Kök kuru ağırlığı, GTA: Gövde taze ağırlığı, \%KKök: Kuru kök yüzdesi, Kİ: Katlılık indisi, FTA: Fidan taze ağırlı̆̆ı, a, b, c: Homojen gruplar

Tablo 5. Uygulama Zaman x EM çeşidi varyans analizi sonuçlarına göre farklılık belirlenmiş morfolojik karakterlere ait Duncan testi sonuçları.

\begin{tabular}{|c|c|c|c|c|c|c|c|c|c|c|}
\hline \multirow{2}{*}{$\begin{array}{l}\text { Uygulama } \\
\text { Zaman x EM } \\
\text { çeşidi }\end{array}$} & \multicolumn{5}{|l|}{ Nisan-Mayıs } & \multicolumn{5}{|c|}{ Haziran-Temmuz } \\
\hline & EM-1 & EM-A & EM-5 & EM-GOLD & KONTROL & EM-1 & EM-A & EM-5 & EM-GOLD & KONTROL \\
\hline \multicolumn{11}{|c|}{ Aritmetik Ortalama ve Standart Hata $\left(X+S_{x}\right)$} \\
\hline Fidan boyu & $18,4 \pm 0,47 \mathrm{ab}$ & $18,5 \pm 0,56 \mathrm{ab}$ & $19,9 \pm 0,49$ a & $19,5 \pm 0,50$ a & $17,0 \pm 0,87 \mathrm{~b}$ & $18,0 \pm 0,47 \mathrm{~b}$ & $18,9 \pm 0,5 \mathrm{ab}$ & $18,0 \pm 0,47 \mathrm{~b}$ & $19,1 \pm 0,45$ a & $18,9 \pm 0,85 \mathrm{ab}$ \\
\hline Kök boğaz çapı & $4,64 \pm 0,12$ bc & $5,04 \pm 0,12 \mathrm{ab}$ & $4,95 \pm 0,12 \mathrm{ab}$ & $5,18 \pm 0,15$ a & $4,26 \pm 0,22 \mathrm{c}$ & $5,34 \pm 0,15$ a & $4,91 \pm 0,11 \mathrm{ab}$ & $5,02 \pm 0,12 \mathrm{ab}$ & $4,92 \pm 0,13 \mathrm{ab}$ & $5,05 \pm 0,23 \mathrm{ab}$ \\
\hline Gövde taze ağır. & $4,69 \pm 0,21$ bc & $5,54 \pm 0,27 \mathrm{ab}$ & $4,93 \pm 0,21$ abc & $4,77 \pm 0,22 \mathrm{abc}$ & $5,53 \pm 0,55 b$ & $5,63 \pm 0,27$ a & $4,37 \pm 0,18 \mathrm{c}$ & $4,62 \pm 0,23 \mathrm{bc}$ & $4,65 \pm 0,25$ bc & $5,03 \pm 0,55 a b c$ \\
\hline Fidan taze ağır. & $8,86 \pm 0,41 \mathrm{ab}$ & $9,94 \pm 0,39 a b$ & $8,74 \pm 0,39 \mathrm{ab}$ & $8,48 \pm 0,42 \mathrm{~b}$ & $10,1 \pm 1,0 \mathrm{ab}$ & $10,25 \pm 1,0$ a & $8,46 \pm 0,37 \mathrm{~b}$ & $8,93 \pm 0,42 \mathrm{ab}$ & $8,42 \pm 0,5 b$ & $10,05 \pm 1,0 \mathrm{ab}$ \\
\hline D. kalite indisi & $0,59 \pm 0,01 \mathrm{ab}$ & $0,63 \pm 0,01$ a & $0,58 \pm 0,01 \mathrm{ab}$ & $0,58 \pm 0,01 \mathrm{ab}$ & $0,62 \pm 0,02 \mathrm{ab}$ & $0,63 \pm 0,01$ a & $0,60 \pm 0,01 \mathrm{ab}$ & $0,60 \pm 0,01 \mathrm{ab}$ & $0,57 \pm 0,09 \mathrm{~b}$ & $0,62 \pm 0,02 \mathrm{ab}$ \\
\hline
\end{tabular}




\section{Sonuç ve Tartışma}

EM çoğu Avrupa ülkelerinde özellikle tarımsal alanlar başta olmak üzere birçok alanda yaygın bir şekilde kullanılmaktadır. Bu konuda; Hollanda, Japonya ve Kore gibi ülkelerde tarım alanlarında yapılan çalışmalara rastlanmıştır. Elde edilen sonuçlar, EM preparatlarının toprağın üretim özelliklerinin iyileştirilmesi üzerine olan olumlu etkisi hakkındaki mevcut görüşleri doğrular niteliktedir (Higa ve Wididana, 1991; Valarini vd., 2003). Daly ve Stewart (1999) çalışmalarında, EM’lerin topraktaki organik maddenin mineralleşmesini hızlandırdığını belirtmişlerdir. Ayrıca EM'ler, bitkiler için daha fazla miktarda beslenme formu ve toprak asiditesinin azalması, anaç bitkilerin hem yer altı hem de yer üstü kısımlarında büyüme parametrelerinde belirgin bir iyileşmeye neden olduğu belirtilmektedir. EM kullanımı ekolojik tarımın gelişmesi için de büyük önem arz etmektedir. EM’ler yararlı toprak mikro florasının arttırılması, bitkilerin vejetatif büyümesini iyileştirilmesi, böcek hastalıklarına ve zararlılara karşı direncinin arttırılmasında da olumlu etkileri bulunan doğal ürünler olarak ifade edilmektedir (Daly ve Stewart, 1999). EM bitki büyümesi, verimi ve kalitesi üzerindeki olumlu etkileri birçok çalışma ile ortaya konmasına rağmen, topraktaki belirli kimyasal, fiziksel ve mikrobiyolojik problemleri hafifletmek için hangi EM kültürlerinin veya bunların hangi kombinasyonlarının en etkili olduğu konusunda hala birçok soru vardır (Higa ve Wididana, 1991). EM kullanımı özellikle tarımda yaygın olmakla birlikte tarla bitkilerinde de sıkça kullanılmasına (Chaudhry vd., 2005; Piskier, 2006; Javaid, 2006) rağmen ormancılıkta ise etkinliği ile ilgili bilgiler oldukça sınırlıdır.

Bu araştırmanın sonuçlarına göre; KTA ve \%KKök değişkenleri üzerinde en olumlu tesiri EM-1 yaparken, EM uygulamalarının orta ve yüksek dozlarının KBÇ, GTA, FTA, \%KKök ve Gİ karakterleri üzerinde olumlu etkisi tespit edilmiştir. Ayrıca, EM uygulamasının zamanı açısından vejetasyon dönemi içinde, haziran ayında, yapılan aplikasyonun KBÇ ve \%KKök üzerinde olumlu etkisi saptanmıştır. Diğer bir ifadeyle; EM'lerin uygulanma zamanının fidan morfolojik karakterleri üzerinde etkili olduğu, KBÇ açısından Haziran-Temmuz aylarında yani vejetasyon dönemi içerisinde uygulanan EM işleminin vejetasyon dönemi dışındaki uygulamaya göre daha tesirli olmuştur. Bu araştırma sonuçlarını teyid eder şekilde, Atik (2008), 2+0 yaşlı doğu kayını fidanları üzerinde yürüttükleri araştırmada; doğal madde uygulamalarının (Baykal ve EM-1) kontrol fidanlarına göre çap gelişimini arttırdığını belirtmişlerdir. Ertekin vd., (2009) ise defne fidanlarının gelişiminde polystimulin (PS A6-K), Giberillin $\left(\mathrm{GA}_{3}\right)$ ve farklı katlama sürelerinin etkisini saptamak amacıyla yaptı̆̆ çalışmada en yüksek KBÇ’yi $5,8 \mathrm{~mm}$ ile 30 gün soğuk katlamaya maruz bırakılan fidanlardan elde etmiştir. Özellikle ekstremite arz eden yetişme muhitlerinde fidan yüzdesi için önem arz eden KBÇ’nin (Öner vd., 2016), EM kullanımı ile artabileceği ve böylece yarı kurak ve antropojen step mıntıkalarının ağaçlandırmasında daha fazla başarı elde edilebileceği düşünülmektedir.

Araştırmada; EM çeşidi ve uygulama zamanı faktörlerinin etkileşimli etkileri irdelendiğinde; Vejetasyon dönemi öncesinde EM-5 ve EM-GOLD, vejetasyon dönemi içi uygulamalarda ise EM-GOLD çeşidinin FB üzerinde olumlu tesiri saptanırken, KBÇ, GTA ve FTA karakterleri üzerinde vejetasyon dönemi içerisinde uygulanan EM1 çeşidinin en olumlu etkiyi yaptığı belirlenmiştir. Dickson kalite indisi üzerinde ise vejetasyon dönemi öncesinde EM-A, vejetasyon dönemi içinde ise EM-1 uygulamalarının en olumlu etkiyi yaptığı tespit edilmiştir. Zydlik ve Zydlik (2008) EM-A ve EM-5'in de etkili bir karışım olduğu, uygulanan topraklarda organik madde mineralizasyonunu ve yaprakların asimilatif yüzeyinin büyümesini arttırdığını belirtmişlerdir. Dönmez (2009), Baykal EM-1 ve Biyohumus'un Amaranthus türleri üzerindeki boy gelişimine olan etkisini incelediği araştırmada A. caudatus var. bulava için boy gelişimini Mayıs, Temmuz ve Ekim aylarına göre değerlendirmiştir. Çalışma sonucunda; Mayıs ayı itibarı ile en yüksek boy gelişimini Baykal EM-1 uygulamasında, kontrol grubuna göre \% 15 daha fazla; Temmuz ayında Baykal EM-1 + Biyohumus uygulanan fidanlarda kontrol grubuna göre \% 33 daha fazla; Ekim ayında ise \%36 artış ile Baykal EM-1 uygulanan fidanlar da en yüksek boy gelişimi gözlemlenmiştir. Yine Apaza-Gutierrez (2002) A. caudatus'un kimyasal ve organik gübre karışımı ile muamele edildiğinde boy uzamasının \%25 oranında arttığını belirtmiştir. Mohammed vd., (2013) araştırmalarında; kahve bitkisi tohumlarının 4,5 saat süreyle EM çözeltisinde bekletildikten sonra orman toprağına ekilen bu tohumlardan gelişen fideciklerin; en yüksek fide boyu, birincil dal sayısı ve toplam kuru madde geliştirdiğini ifade etmişlerdir.

Plastitesi yüksek bir tür olan ve ağaçlandırma çalışmalarında farklı ekolojilerde de tercih edilen Toros sedirinin (Ayan vd., 2017) uygun EM dozu kullanımı ile başarı oranının artacağı düşünülmektedir. Uygulanan orta ve yüksek EM dozlarının düşük doz uygulamasına göre daha tesirli olduğu saptanmıştır. KTA üzerinde ise hem EM çeşidi hem de EM dozu anlamlı etki yapmıştır. Dönmez (2009) çalışmasında; Baykal EM1+Biyohumus ile muamele ettiği A. caudatus var. bulava'da, Baykal EM1+Biyohumus’un kontrol grubuna göre \% 24 oranında KTA’da bir artış saptamıştır.

\%KKök değişkeni üzerinde EM çeşidi, uygulama dozu ve zamanı faktörlerinin her biri ayrı ayrı istatistiki bakımından anlamlı etki yaptığı saptanmıştır. En yüksek \%KKök değeri \%52,3 ile EM-1 uygulamasından elde 
edilmiştir. EM-1 içeriğinin tarımda uygulanan ana ürün olması ve EM'lerin bütün faydalı özelliklerini içermesi daha iyi sonuç elde edilmesinde etkili olmuş olabilir. Vejetasyon dönemi içindeki EM uygulamasının \%52,1'lik \%KKök değeri ile vejetasyon dönemi öncesi uygulamaya göre daha olumlu etkisi olmuştur. Bu sonuçlar; Toros sediri fidanlarının özellikle yarı kurak ve antropojen step sahaların ağaçlandırmasında daha güvenle kullanılmasına vesile olabilecektir. Çünkü bu alanlarda KBÇ, KKA ve \%KKök gibi karakterler bakımından kök sistemi avantajı olan fidanların tutma ve gelişme potansiyeli daha yüksek olabilecektir. Ayrıca, Boydak (1986) Toros sedirinin oluşturduğu kök sistemiyle ağaçlandırma çalışmalarında özellikle karstik alanlarda tutma başarısı yüksek olan bir tür olduğunu, kazık kök ve buna bağlı sekonder köklerini ilk yıllarda hızla geliştirdiğini buna karşın, sak gelişimini ise transpirasyonu azaltacak derecede yavaşlattığını vurgulamaktadır. Zydlik ve Zydlik (2008) EM uygulanan elma ağaçlarının iyi gelişmiş kök sistemi oluşturduğunu ayrıca, bitkinin yer üstü organlarının gelişimi üzerinde de olumlu tesirinin olduğunu vurgulamışlardır.

EM uygulamaları, iklim değişikliği sebebiyle meydana gelen başta kuraklık olmak üzere olumsuz çevre koşullarından bitkilerin daha az etkilenmesi, tutma ve gelişim performanslarına olası olumlu etkileri nedeniyle farklı ağaç türü fidanları için değişik ekolojik koşullarda denenmesinin uygun olduğu düşünülmektedir.

\section{Kaynaklar}

1. Apaza-Gutierrez, V., Romero-Saravia, A., Guillèn-Portal, F.R., Baltensperger, D.D. (2002). Response of Grain Amaranth Production to Density and Fertilization in Tarija, Bolivia. in: J. Janick and A. Whipkey (eds), Trends in New Crops and New Uses. ASHS Press Alexandria, V.A. p:107-109

2. Aphalo, P., Rikala, R. (2003). Field performance of silver-birch planting-stock grown at different spacing and in containers of different volume. New Forests, 25(2), 93-108.

3. Arakawa, Y. (1985). Effects of EM application on snow thawing as well as snow rotting and powdery mildew problems of crops (Part V). Proceedings of Symposium of Applied Soil Microbiology. November 22, 1985, Urazoe, Okinawa, Japan.

4. Ata, C. (1995). Silvikültür Tekniği. Zonguldak Karaelmas Üniversitesi Yayın No:4/3, 453 s, Bartın.

5. Atik, A. (2013). Effect of different concentrations of effective microorganisms (Baikal EM1) on the root collar diameter and height growth in the seedlings of Anatolian black pine [Pinus nigra Arnold. subsp. pallasiana Lamb. (Holmboe)]. International Journal of Food, Agriculture \& Environment, 11(2), 13001304.

6. Atik, H.A. (2008). Doğal Maddelerin (Biyohumus ve Baykal EM1) Doğu Kayınında (Fagus orientalis Lipsky.) Bazı Morfolojikfizyolojik Proseslere Etkisi. Doktora Tezi, Zonguldak Karaelmas Üniversitesi, Fen Bilimleri Enstitüsü Orman Mühendisliği Anabilim Dalı, Zonguldak, Türkiye, s. 1-389.

7. Avanoğlu, B., Ayan, S., Demircioğlu, N., Sivacioğlu, A. (2005). The Evaluation of 2+ 0-year old Black pine (Pinus nigra Arnold. subsp. pallasiana (Lamb.) Holmboe.) seedlings produced in Kastamonu-Taşköprü Forest Nursery according to the norms of Turkish Standards Institution, SIGMA. Journal of Engineering and Science, Yıldiz Technical University, 2, 73-83.

8. Ayan, S. (1998). The effects of slow release fertilizer on the production of containerized-scotch pine (Pinus sylvestris L.). Journal of Forest Engineering, 35 (9), 25-28.

9. Ayan, S. (1999). Tüplü Doğu Ladini (Picea orientalis Lipsky.) Fidanlarının Yetiştirme Ortamları Özelliklerinin Tespiti Ve Üretim Tekniğinin Belirlenmesi. Doktora Tezi, Karadeniz Teknik Üniversitesi, Fen Bilimleri Enstitüsü, Trabzon, Türkiye, s 157.

10. Ayan, S. (2002a). Determining the site condition features of Containerized-Oriental Spruce (Picea orientalis (L.) Link.) seedlings; and setting the production Techniques, Ministry of Forests, the Institution of Eastern Black Sea Forestry Research, Ministry Publication number: 179, Eastern Black Sea Forestry Studies (DKOA) Publication number: 14. Technical Bulletin Publication, (11).

11. Ayan, S. (2007). Containerised Seedling Propagation, 7th Section (Editors: Yahyaoğlu, Z. and M. Genç, Seedling Standardization: Quality Seedling Propagation and Principals of Seedling Qualification Norms) Publication of Suleyman Demirel University, Pub. Nu: 75, P. 301-352, ISBN 978-9944-452-07-6, Isparta.

12. Ayan, S. (2015). A Review on Rehabilitation and Afforestation Experiences of Cedrus libani A. Rich in Turkey, Ecoplantmed Conference, 12-15 October, Beirut, Lebanon.

13. Ayan, S. (2001). Fidan üretiminde topraksız kültür ortamı alternatifleri, Gazi Üniversitesi Orman Fakültesi Dergisi, 1(1): 30-42, Kastamonu.

14. Ayan, S. (2002b). Fidan yetiştiriciliği ve ağaçlandırma çalışmalarında zeolite mineralinin kullanımı, Gazi Üniversitesi Orman Fakültesi Dergisi, 2(1): 78-88, Kastamonu. 
15. Ayan, S., Civek, E., Yer Çelik, E.N., Gülseven, O., Akin, Ş.S., Yilmaz, E. (2020a). Morphological quality characteristics of Mediterranean and Arizona cypresses seedlings. Journal of Bartın of Faculty of Forestry, 22(2), 580-590. Doi: 10.24011/Barofd.707871

16. Ayan, S., Civek, E., Yer Çelik, E.N., Gülseven, O., Özel, H.B., Eshaibi, J.A.H., Akin, Ş.S., Yilmaz, E. (2020b). Morphological quality characteristics of different ages containerised seedlings of stone pine (Pinus pinea L.). Journal of Bartın of Faculty of Forestry, 22(2), 633-641. Doi: 10.24011/Barofd.720658

17. Ayan, S., Feyzioğlu, F., Demircioğlu, N., Aksu, V. (2005b). Growth Periods of Oriental Spruce Seedlings (Picea orientalis Link.) in The Ecological Conditions of Trabzon-Of Forest Nursery. Symposium On Spruce, Trabzon, Türkiye, Vol. 1, P; 437-445,

18. Ayan, S., Gedik, F., Yer Çelik, E.N., Gülseven, O., Yilmaz, E., Akin, Ş.S., Özel, H.B. (2020c). Morphological characteristics of some broad-leaved forest tree seedlings, Journal of Bartın of Faculty of Forestry, 22(1), 245-255.

19. Ayan, S., Gerçek, V., Şahin, V., Sivacioğlu, A. (2005a). Tüplü doğu ladini (Picea orientalis (L.) Link.) fidanı üretiminde substrat olarak zeolitin kullanılabilirliği. Karadeniz Teknik Üniversitesi, Ladin Sempozyumu, 19-22 Ekim 2005, Trabzon, Türkiye, Cilt. 1, S. 490-500.

20. Ayan, S., Tilki, F. (2007). Morphological attributes of oriental spruce [Picea orientalis (L.) Link.] seedlings grown in peat-based media amended with natural zeolite. Acta Agronomica Hungarica, 55(3), 363-373.

21. Ayan, S., Tüfekçioğlu, A. (2006). Growth responses of Scots pine seedlings grown in peat-based media amended with natural zeolite. Journal of Environmental Biology, 27(1), 27-34.

22. Ayan, S., Turfan, N., Yer, E.N., Özel, H.B., Seho, M., Ducci, F. (2018). Antioxidant variability of the seeds in core and marginal populations of taurus cedar (Cedrus libani A. Rich.). Sumarsky List, 142(11-12), 593-600.

23. Ayan, S., Turna, İ., Acar, C. (2000). The effects of greenhouse and outdoor conditions on several morphological characteristics of Enso-type Scotch Pine (Pinus sylvestris L.) seedlings. Journal of Eastern Anatolian Forestry Research Institute, (3), 64-76.

24. Ayan, S., Yer, E.N. (2016). Assessment of Taurus Cedar (Cedrus libani A. Rich) plantations out of their natural distribution areas in Turkey with regards to ecological factors. In International Symposium on Forest areas and peri-urban forests" Dynamics and Challenges, 11 Abstract Book (p. 10).

25. Ayan, S., Yer, E.N., Gülseven, O. (2017). Türkiye'deki Toros sediri (Cedrus libani A. Rich.) ağaçlandırma sahalarının iklim tipi açısından değerlendirilmesi. Artvin Çoruh Üniversitesi Orman Fakültesi Dergisi, 18(2), 152-161.

26. Ayıntaplı, P. (1995). Serinyol ve Tekir fidanlıklarında üretilen Kızılçam, Anadolu Karaçamı ve Toros Sediri fidanlarında kalite sınıflaması araştırmaları. Yüksek Lisans Tezi, Karadeniz Teknik Üniverstesi, Fen Bilimleri Enstitüsü, Trabzon, Türkiye, s 116.

27. Boydak, M. (1986). Lübnan (Toros) Sedirinin (Cedrus libani A. Rich.) yayılışı, ekolojik ve silvikültürel nitelikleri, doğal ve yapay gençleştirme sorunları. Ormancılık Araştırma Enstitüsü Dergisi, No:64, Sf:7-55.

28. Chagas, P.R., Tokeshi, H., Alves, M.C. (2001). Effect of Calcium on Yield of Papaya Fruits on Conventional and Organic (Bokashi Em) Systems. Proceeding of The $6^{\text {th }}$ International Conference on Kyusei Nature Farming, South Africa, Pp. 255-258.

29. Chaudhry A.N., Latıf M.I., Khan A.A., Ghulam, J., Tanveer I. (2005). Comparison of Chemical Fertilizer with Organic Manures by Using Effective Microorganisms Under Maize Cropping İn Rained Areas. International Journal Biology and Biotechnology, 2 (4) 1001-1006.

30. Daly, M.J., Stewart D.P.C. (1999). " Influence of “effective microorganisms"(EM) on vegetable production and carbon mineralization-a preliminary investigation. Journal of Sustainable Agriculture, 14(2-3), 15-25.

31. Demircioğlu, N., Ayan, S. (2004). Growth Periods of Scots Pine seedlings (Pinus sylvestris L.) in the Ecological Conditions of Kastamonu-Taşköprü Forest Nursery, 5th National Congress on Ecology and Environment, Nature and Environment, Bolu, Turkey, p. 107-114,

32. Demircioğlu, N., Ayan, S., Avanoğlu, B., Sivacioğlu, A. (2004). Kastamonu-Taşköprü orman fidanlığında üretilen 2+0 yaşlı sarıçam (Pinus sylvestris L.) fidanlarının TSE normlarına göre değerlendirilmesi, Pamukkale Üniversitesi Mühendislik Bilimleri Dergisi, 10(22), 243-251.

33. Dickson, A., Leaf, A.L., Hosner, J.F. (1960). Quality appraisal of white spruce and white pine seedling stock in nurseries. The Forestry Chronicle, 36(1), 10-13.

34. Dönmez, Ş. (2009). Bartın İklim Koşullarında Doğal Maddelerin (Baykal EM1 ve Biyohumus) Amaranthus Caudatus var. bulava ve Amaranthus tricolor var. valentina'da Bazı Morfolojik Ve Fizyolojik Proseslere Etkisi Ve Bu Bitkilerin Peyzaj Mimarlı̆̆ında Kullanımı, Bartın Üniversitesi, Bartın, Türkiye, s. 275.

35. Eler, Ü., Keskin, S., Örtel, E. (1993). Toros sediri (Cedrus libani A. Rich.) fidanlarında kalite sınıflarının belirlenmesi üzerine araştırmalar. Ormancılık Araştırma Enstitüsü Dergisi, 240, 81-105. 
36. Ertekin, M., Kırdar, E., Özel, H.B. (2009). Bazı büyüme düzenleyicilerin Akdeniz Defnesi (Laurus nobilis L.) fidanlarının gelişimi üzerine etkileri. Kastamonu Üniversitesi Orman Fakültesi Dergisi, 9(2), 171-176.

37. Fujita, M. (2000). Nature farming practices for apple production in Japan. Journal of Crop Production, 3(1), 119-125.

38. Genç, M. (1992). Doğu ladini (Picea orientalis (L.) Link.) fidanlarına ait bazı morfolojik ve fizyolojik özelliklerle dikim başarısı arasındaki ilişkiler. Yayınlanmamış Doktora Tezi, Karadeniz Teknik Üniversitesi, Fen Bilimleri Enstitüsü, Trabzon, Türkiye, s, 284.

39. Gülseven, O., Ayan, S., Özel, H.B., Yer, E.N. (2019). Morphological and physiological characteristics of saplings of different Eastern beech populations (Fagus orientalis Lipsky.). Turkish Journal of Forestry, 20(3), 180-186.

40. Higa, T. (1998). Effective Microorganisms for a more sustainable agriculture, environment and society: Potential and prospects. In Proceedings of the Fourth International Conference on Kyusei Nature Farming, Paris (pp. 12-13).

41. Higa, T., Parr, J.F. (1994). Beneficial and effective microorganisms for a sustainable agriculture and environment (Vol. 1). Atami: International Nature Farming Research Center. Atami, Japan. 16 Pp.

42. Higa, T., Wididana, G.N. (1991). The concept and theories of effective microorganisms. In Proceedings of the first international conference on Kyusei nature farming. US Department of Agriculture, Washington, DC, USA, pp. 118-124.

43. Iwahori, H., Nakagawara T. (1996). Studies On EM Application in Nature Farming. V. Applying Methods of EM Bokashi İn Vegetable Cultures. Annual Meeting of Japanese Society of soil Science and Plant Nutrition, April 1996, Tokyo, Japan.

44. Iwaishi, S. (1994). Effects of Em Bokashi On Various Paddy-Rice Varieties. Annual Meeting of AsiaPacific Nature Agriculture Network. October 6, 1994, Seoul, Korea.

45. Javaid, A. (2006). Foliar application of effective microorganisms on pea as an alternative fertilizer. Agronomy for Sustainable Development, 26(4), 257-262.

46. Kulaç, Ş. (2016). Gübrelemenin Kayacık (Ostrya carpinifolia Scop.) fidanlarının morfolojik gelişimine etkisi. Türk Tarım-Gıda Vilim Ve Teknloji Dergisi, 4(10), 813-821.

47. Mohamed, E.A. (2013). Growth performance and physiological characteristics of seedlings of six tropical dry land forest tree species in the Sudan. Journal of Natural Resources and Environmental Studies, 1(2), 25-33.

48. Mohammed, A., Gebreselassie, W., Nardos, T. (2013). Effect of Effective Microorganisms (EM) Seed Treatment and Types of Potting Mix on the Emergence and Growth of Coffee (Coffea arabica L.) Seedlings. International Journal of Agricultural Research, 8: 34-41.

49. Öner, N., Erşahin, S., Ayan, S., Özel, H.B. (2016). İç Anadolu’da yarı kurak alanların rehabilitasyonu, Anadolu Orman Araştırmaları Dergisi, 2(1-2), 32-44.

50. Özdemir, S. (1989). Çukurova Bölgesinde Azot, Fosfor Ve Potasyum Uygulamasının Nohut Bitkisinde Verim ve Verimle İlgili Bazı Morfolojik ve Fizyolojik Karakterlere Etkisi. Yüksek Lisans Tezi, Çukurova Üniversitesi, Adana, Türkiye, s 42.

51. Piskier, T. (2006). Reakcja pszenicy jarej na stosowanie biostymulatorów i absorbentów glebowych. Journal of Research and Applications in Agricultural Engineering, 51(2), 136-138.

52. Que'Zel P, Me'Dail, F. (2003). Ecologie Et Bioge'Ographie Des Fore`ts Du Bassin Me’Diterrane’En. Elsevier, Paris, PP. 576.

53. Şevik, H., Ayan, S., Demircioğlu, N., Sivacioğlu, A. (2003). The evaluation of bare-rooted and broadleaved forest tree seedlings grown in Gölköy forest nursery (province of Kastamonu) according to the norms of Turkish Standards Institution. Journal of Forestry Faculty of Gazi University, 3(2), 233-245.

54. Suzuki, Y. (1985). Effects of Effective Microorganisms On Yield and Quality of Gin- Seng Herbs. Symposium of Applied Soil Microbiology. November 22, 1985, Ura- Zoe, Okinawa.

55. URL-1 http://www.emturkey.com.tr Erişim tarihi: 02/04/2018

56. URL-2 https://buildasoil.com/products/em-1-microbial-inoculant?variant=8779501895797 Erişim tarihi: 01/02/2021

57. URL-3 https://asertarim.com.tr/urunlerimiz/ema-canli-bakteri-20-lt-Sivas Erişim tarihi: 01/02/2021

58. URL-4 https://www.pttavm.com/mikrobiyal-gubre-em-5-1-lt-p-84195047 Erişim tarihi: 01/02/2021

59. URL-5 http://www.em-produkte.de/EM-X-Gold-500ml Erişim tarihi: 01/02/2021

60. Valarini P.J., Diaz Alvares M.C., Gasco J.M., Guerrero F., Tokeshı, H. (2003). Assessment of soil properties by organic matter and EM-microorganism incorporation. Revista Brasileira de Ciência do Solo, 27(3), 519-525.

61. Yahyaoğlu, Z., Genç, M. (2007). Kalite Sınıflaması Çalışmaları ve Türkiye İçin Öneriler, Fidan Standardizasyonu (Standart Fidan Yetiştirmenin Teknik ve Biyolojik Esasları), Süleyman Demirel Üniversitesi, Orman Fakültesi Yayın No: 75, Isparta (Türkiye). 
62. Yer, E. N., Ayan, S. (2011). Growth stages of bare rooted seedlings of taurus cedar and anatolian black pine in Eskişehir forest nursery conditions. Journal of Forestry Faculty Kastamonu University, 11(2), 219227.

63. Yılmaz, H. (1988). Fertilization of Nurseries and Fixation Question of Some Plant Nutrient in Nursery Lands. Journal of Poplar and Fast Growing Forest Trees Research Institute, (1):1-7.

64. Zimmermann, I., Kamukuenjandje, R.T. (2008). Overview of a variety of trials on agricultural applications of Effective Microorganisms (EM). Agricola, 8, 1-24.

65. Zydlik, P., Zydlik, Z. (2008). Impact of Biological Effective Microorganisms (EM) Preparations on Some Physico-Chemical Properties of Soil and The Vegetative Growth of Apple-Tree Rootstocks. Nauka Przyroda Technologie, 2(1), 4. 